\title{
Partial androgen insensitivity syndrome presenting as pubertal gynecomastia: clinical and hormonal findings and a novel mutation in the androgen receptor gene
}

\author{
Priya Vaidyanathan and Paul Kaplowitz \\ Division of Endocrinology, Children's National Health System, Washington, District of Columbia, USA
}

Correspondence should be addressed to $P$ Vaidyanathan

Email

pvaidyan@childrensnational. org

\section{Summary}

Pubertal gynecomastia is common, can be seen in $65 \%$ of the adolescent boys and is considered physiological. It is thought to be due to transient imbalance between the ratio of testosterone and estradiol in the early stages of puberty. It resolves in 1-2 years and requires no treatment. However, more persistent and severe pubertal gynecomastia is less common and can be associated with pathological disorders. These can be due to diminished androgen production, increased estrogen production or androgen resistance. We report a case of persistent pubertal gynecomastia due to partial androgen insensitivity syndrome (PAIS), classical hormone findings and a novel mutation in the androgen receptor (AR) gene.

\section{Learning points:}

- Laboratory testing of follicle-stimulating hormone (FSH), leutinizing hormone (LH) and testosterone for pubertal gynecomastia is most helpful in the setting of undervirization.

- The hormonal finding of very high testosterone, elevated LH and estradiol and relatively normal FSH are classical findings of PAIS.

- Gynecomastia due to PAIS will not resolve and surgery for breast reduction should be recommended.

\section{Background}

This case describes presentation, diagnosis and treatment of a rare cause of pubertal gynecomastia. The diagnosis was important for proper management of the condition and led to the identification of a novel AR gene mutation.

\section{Case presentation}

A healthy, 17-year and 7-month-old male was evaluated for persistent and progressive gynecomastia of 3-year duration. Birth and childhood history was unremarkable. He reported onset of puberty about 4 years ago and had not started shaving. He was not taking any medications. There is no family history of gynecomastia. His height was $178.5 \mathrm{~cm}$, (0.4 S.D.), weight was $63 \mathrm{~kg},+0.2$ s.D., BMI $20.6,-0.1$ s.D. He had a normal general and systemic examination. Distinct features were a lack of facial hair, sparse axillary hair, very little body hair, stretched penile length of $8 \mathrm{~cm}(<-2.5$ s.D.), pubic hair tanner stage 3 and testicular volume $15 \mathrm{~mL}$. There was bilateral well developed Tanner 3 breast tissue. There was no nipple discharge. Patient denied being sexually active. Laboratory findings are provided in Table 1. 
Table 1 Laboratory findings.

\begin{tabular}{|c|c|c|}
\hline Parameters & Values & Normal values \\
\hline $\mathrm{FSH}(\mu / \mathrm{mL})$ & 7.7 & $<5.6$ \\
\hline LH $(\mu / m L)$ & 14 & $<3.6$ \\
\hline Testosterone (ng/dL) & 1660 & $<1000$ \\
\hline Free testosterone (pg/dL) & 344.6 & $18-111$ \\
\hline Estradiol (pg/mL) & 64 & $<54$ \\
\hline Estrone (pg/mL) & 51 & $15-65$ \\
\hline Karyotype & $46, X Y$ & \\
\hline
\end{tabular}

\section{Investigation}

Partial androgen insensitivity syndrome (PAIS) was suspected based on the very high total and free testosterone levels, elevated LH level, elevated estradiol level and lack of adequate virilization for the testosterone level in the setting of persistent pubertal gynecomastia.

Molecular analysis of the androgen receptor (AR) gene was done at GeneDx. A novel, A721T missense mutation was detected in the $A R$ gene. He was found to be hemizygous for the $\mathrm{G}>\mathrm{A}$ nucleotide resulting in replacement of the alanine codon with threonine codon at the amino acid position 721 on exon 4 . The variant has been denoted as c. $2161 \mathrm{G}>\mathrm{A}$ at the c.dna level. Further genetic testing on the family was not pursued as he is under the care of his paternal grandmother only. The patient and his grandmother did not recall a family history of gynecomastia or infertility and one could therefore speculate that it is a de novo mutation.

\section{Treatment}

Patient was referred to plastic surgery and successfully underwent bilateral mastectomy. He did not express any desire to start androgen therapy.

\section{Outcome and follow-up}

Patient did not return for follow-up to endocrinology department.

\section{Discussion}

Physiological pubertal gynecomastia is quite common and mild to moderate cases usually resolve spontaneously $(1,2)$. Pathological or persistent gynecomastia in puberty can be due to diminished androgen production (hypo- or hyper-gonadotropic hypogonadism, increased estrogen production from a tumor or familial aromatase excess or androgen resistance/insensitivity).
Androgen insensitivity is caused by a defect in the AR, which is a nuclear transcription factor encoded by the $A R$ gene located on the X chromosome at Xq11-12.1. This results in end-organ resistance to androgens resulting in underandrogenization of varying degree despite normal to high levels of androgens. On one end of this spectrum is the total lack of response to androgens as seen in complete androgen insensitivity syndrome (CAIS). CAIS has a prevalence of 1:64 000 (3). The main characteristics are 46, XY karyotype, female external genitalia, a short, blind ending vagina, an intra-abdominal or inguinal gonad, lack of uterus and oviducts, development of gynecomastia and the absence of pubic and axillary hair. Testosterone levels are elevated at the time of puberty, while also elevated LH levels are found.

PAIS has a prevalence of 1:20 000 (4) and results from a milder AR mutation. Phenotypic presentation can vary from ambiguous genitalia to nearly normal male. PAIS with phenotypically normal male external genitalia can be first noted by the appearance of gynecomastia in puberty as seen in our patient and is to be considered in the differential diagnosis of persistent pubertal gynecomastia. At puberty, elevated LH, testosterone and estradiol levels are observed. The proposed mechanism is a dysfunction of the hypothalamic AR that impairs the negative feedback regulation of LH (and FSH) on the hypothalamic-pituitary-gonadal axis (5) resulting in elevated LH levels despite increased testosterone levels. This leads to increased circulating estradiol levels through aromatization and exerts negative feedback on the hypothalamic-pituitary axis resulting in normal FSH levels. Individuals with mild symptoms of undervirization (mild androgen insensitivity syndrome (MAIS)) and infertility have been described as well. Phenotypic variation between individuals in different families has been described for several mutations.

The AR is encoded by an eight exon gene on the $\mathrm{X}$ chromosome long arm (4). More than 800 mutations in the $A R$ gene have been reported in AIS patients (www. androgendb.mcgill.ca/) (7). The mutation identified in the AR gene in our patient is a novel one, an A721T missense mutation that has not been reported before. While this mutation has not been previously identified as a cause of AIS, it has been reported as somatic mutation in prostate cancer. Shi et al. (8) have studied 44 mutant ARs from human prostate cancer and reported that this particular mutation is associated with reduced androgen activity. Since AIS results from loss of function alteration in the $\mathrm{AR}$, the A721T missense mutation is a strong candidate for this phenotype. The patient has no known family 
history of gynecomastia or infertility and therefore one could speculate that may be a de novo mutation.

We conclude that while most pubertal gynecomastia tends to resolve, patients with persistent severe pubertal gynecomastia, especially if associated with some degree of undervirization, should have a FSH, $\mathrm{LH}$, testosterone and estradiol levels drawn to rule out pathological causes of gynecomastia.

The constellation of very high testosterone, and elevated LH and estradiol, combined with a lack of adequate body and facial hair and impaired phallic growth is suggestive of PAIS and prompts the analysis of the AR. A definite diagnosis of impaired androgen action and long-lasting gynecomastia justify surgical correction.

\section{Declaration of interest}

The authors declare that there is no conflict of interest that could be perceived as prejudicing the impartiality of the research reported.

\section{Funding}

This research did not receive any specific grant from any funding agency in the public, commercial or not-for-profit sector.

\section{Author contribution statement}

Priya Vaidyanathan is the lead author who wrote the manuscript. Paul Kaplowitz edited the manuscript. Dr Kaplowitz is an Editorial Board Member of Endocrinology, Diabetes and Metabolism Case Reports.
Dr Kaplowitz was not involved in the review or editorial process for this paper, on which he is listed as an author.

\section{References}

1 Limony Y, Friger M \& Hochberg Z. Pubertal gynecomastia coincides with peak height velocity. Journal of Clinical Research in Pediatric Endocrinology 20135 142-144. (doi:10.4274/Jcrpe.958)

2 Ma NS \& Geffner ME. Gynecomastia in prepubertal and pubertal men. Current Opinion in Pediatrics 200820 465-470. (doi:10.1097/ MOP.0b013e328305e415)

3 Hughes IA, Werner R, Bunch T \& Hiort O. Androgen insensitivity syndrome. Seminars in Reproductive Medicine 201230 432-442. (https://doi.org/ 10.1055/s-0032-1324728)

4 Brinkmann AO. Molecular basis of androgen insensitivity. Molecular and Cellular Endocrinology 2001179 105-109. (https://doi. org/10.1016/S0303-7207(01)00466-X)

5 Bouvattier C, Carel JC, Lecointre C, David A, Sultan C, Bertrand AM, Morel Y \& Chaussain JL. Postnatal changes of T, LH, and FSH in $46, \mathrm{XY}$ infants with mutations in the AR gene. Journal of Clinical Endocrinology and Metabolism 200287 29-32. (https://doi. org/10.1210/jcem.87.1.7923)

6 Audi L, Fernández-Cancio M, Carrascosa A, Andaluz P, Torán N, Piró C, Vilaró E, Vicens-Calvet E, Gussinyé M, Albisu MA, et al. Novel $(60 \%)$ and recurrent (40\%) androgen receptor gene mutations in a series of 59 patients with a $46, \mathrm{XY}$ disorder of sex development. Journal of Clinical Endocrinology and Metabolism 201095 1876-1888. (doi:10.1210/jc.2009-2146)

7 Hellmann P, Christiansen P, Johannsen TH, Main KM, Duno M \& Juul A. Male patients with partial androgen insensitivity syndrome: a longitudinal follow-up of growth, reproductive hormones and the development of gynaecomastia. Archives of Disease in Childhood 2012 97 403-409. (doi:10.1136/archdischild-2011-300584)

8 Shi XB, Ma AH, Xia L, Kung HJ \& de Vere White RW. Functional analysis of 44 mutant androgen receptors from human prostate cancer. Cancer Research 200262 1496-1502. 